техники, изобретений и рационализаторских предложений/ под общ.рук. Г.М. Лозы. M.:MCXA, 1980. - c.-116.

\title{
Применение диаграммы Исикавы в ресторанном бизнесе
}

\author{
Пашкина А.В., студентка, \\ Санкт-Петербургский государственный экономический университет, \\ 2. Санкт-Петербург \\ E-mail: helene8@yandex.ru
}

\section{Научный руководитель: к.с.н., доцент Печерица Е.В.}

Один из влиятельнейших специалистов в области управления качеством, Каору Исикава (Ишикава), родившийся в 1915 году в Токио, Япония, создал один из наиболее прославленных, простых и эффективных методов исследования и определения причинно-следственных связей, где последствия напрямую зависят от факторов, что позволяет исследовать проблемы предприятия.

В 60-х годах XX века Исикава предложил дополнительно использовать диаграмму для усовершенствования рабочих процессов на промышленных предприятиях в Японии. Этот метод был так же опубликован в книге Исикавы «Introduction to Quality Control» («Контроль качества. Введение») в 1990 году [1].

Диаграмму Исикавы зачастую называют «рыбий скелет», от англ. Fishbone Diagram - диаграмма «рыбьей кости» из-за ее формы, по структуре схожей со скелетом рыбы [2].

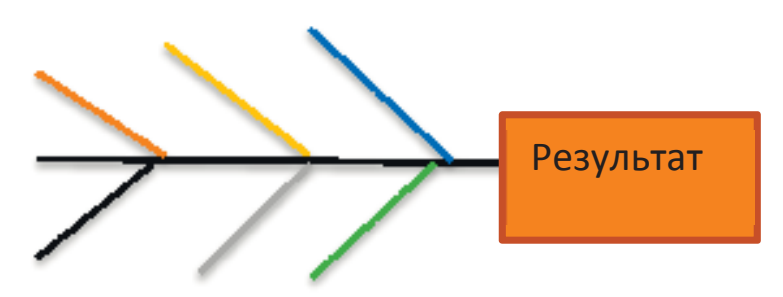

Рис. 1. Пример строения причинно-следственной диаграммы

Для начала анализа с помощью диаграммы Исикавы, необходимо понять, из чего она состоит.

Так как диаграмма предназначена для нахождения изначальных причин, влияющих на качество производства, начнем с основного:

- диаграмма представляет собой графический рисунок, заключающий в себя факторы (первичные, вторичные, третичные и т.д.), влияющие на результат.

- для визуализации диаграммы, необходимо выделить объект анализа результат, на который влияют вышеупомянутые факторы.

- каждая из стрелок-факторов обозначает причину или следствие, в зависимости от ее местонахождения.

После построения диаграммы, необходим анализ, так называемый «мозговой штурм», который, в конечном итоге, приведет к решению проблемы. 
Особенности построения диаграммы Исикавы:

1. С помощью помощников (в случае с большим количеством возможных факторов воздействия), сформулировать и вывести четкое понятие проблемы.

2. Обозначить «голову рыбы» (результат) на схеме с левой или правой стороны, от нее, горизонтально провести «хребет». Расположение «головы» никак не влияет на ход анализа.

3. Основные факторы, влияющие на результат, располагаются под наклоном и присоединяются к «хребту».

4. Далее, к основным «костям» прилегают более мелкие-второстепенные факторы.

5. Наносятся последующие факторы, третьестепенные и т.д., если они были выявлены, иначе, второстепенные «кости» остаются пустыми.

6. Делая анализ и нанося «кости» на график, должны учитываться все факторы, даже, на первый взгляд, не значительные.

7. Факторы должны быть грамотно обозначены и противопоставлены друг другу, это поможет в дальнейшем анализе.

8. Важна детализация. В структуре «рыбы» могут присутствовать даты, имена, названия изделий и т.д.

9. Сам анализ и предшествующие ему действия являются наиболее весомыми для дальнейшего воздействия на результат.

10. «Почему?». Этот вопрос должен возникать при внесении в график любого нового фактора, так как именно ответ на этот вопрос может быть главной причиной, влияющей на результат [3,4].

Достоинства данного метода очевидны. Это простой метод, который помогает подходить к решению проблем творчески и неординарно, а также, находить основополагающие связи между факторами, в дальнейшем, влияющих на результат.

Недостатки у диаграммы так же имеются [5,6].

Во-первых, сложная конструкция. Четкости и упорядоченности в схеме будет становиться меньше, если возможных факторов, воздействующих на результат очень много.

Во-вторых, диаграмму невозможно проверить, то есть вернуться от результата к первопричине практически невозможно [6].

На сегодняшний день, диаграмма используется во всех отраслях производства, в каждой стране мира, что доказывает ее универсальность и простоту.

На основе подготовленной информации о предприятии общественного питания, а именно ресторана Марчеллис на Невском проспекте, 21, построим диаграмму Исикавы, с помощью которой будет найден фактор, отрицательно сказывающийся на качестве услуги, а также, предложены варианты ее решения.

Для выяснения проблемы, были взяты несколько анкет, присланных центром качества ресторана в период с сентября по октябрь 2016года.

Анализируя диаграмму (рисунок 2), можно выделить пять возможных факторов, влияющих на долгую отдачу напитков баром. 


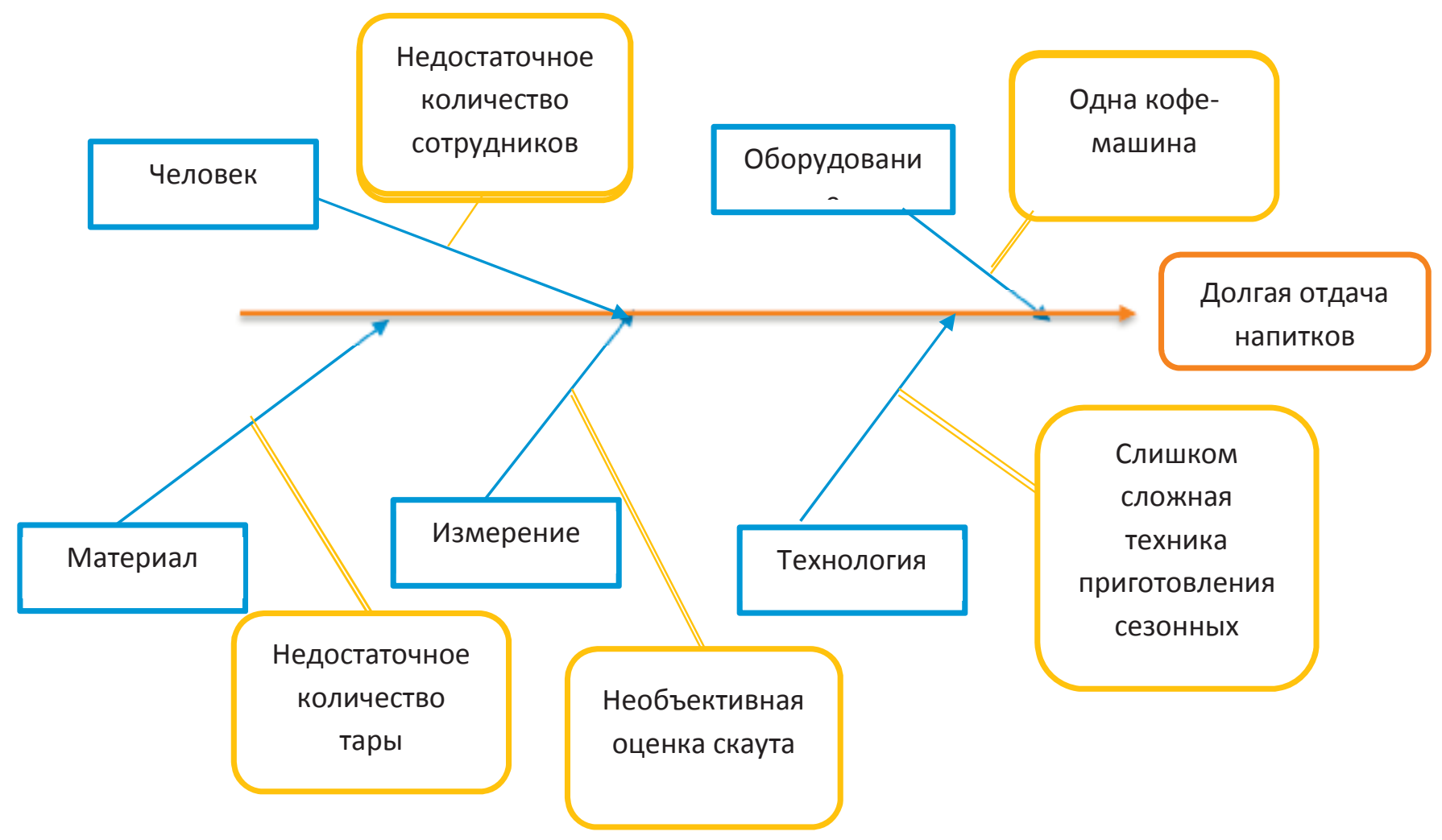

Рис. 2. Применение диаграммы Исикавы

-Возможность того, что задержка происходит из-за недостатка количества сотрудников достаточно велика, так как в период с 12 до 14 часов сотрудник находится один, и только в 14 часов выходит усиление. Но, при угрозе задержки в этот двухчасовой период, страховку бармену обеспечивает менеджер зала.

-Недостаточность тары возможна только при одновременном заказе коктейлей в стаканах «Олд фешн» от 20 порций, на период бизнес ланча, алкогольные коктейли не распространены. Отдача сока или морса распределена на тару, с возможностью отдавать заказы всему залу, при этом, не отдавая тару в мойку.

-Необъективная оценка скаута маловероятна, так как тайминг легко отследить по чеку, который появляется в момент заказа.

-Одна кофе-машина справляется со своим функционалом, так как технология приготовления кофе и кофейных коктейлей происходит в несколько этапов, большинство из которых не требуют задействования машины (за исключением Эспрессо, Американо).

-Сложная технология приготовления является основной проблемой в этой ситуации. Отдача напитков из перечня Бизнес ланча не требудет много времени, однако, если среди чеков на чай/кофе/сок появляется заказ чая «Френч-пресс», коктейлей или Смузи, это значительно задерживает бармена на 5-8 минут, соответственно, идет задержка на позиции Ланча.

Итак, основная проблема выявлена. Осталось предложить экономически правильное решение.

Предложить решение не сложно - вывести усиление раньше, но ведь нет гарантии, что в данный период появится активная загрузка на баре. Из этого следует, что второму бармену оплатят два лишних часа, в которые он не будет рационально работать. 
Но, существует такая штатная единица, «Бар бэк», вспомогательное средство, с нормированным графиком и меньшей почасовой оплатой труда, идущее в усиление, при этом не затрагивая график основных сотрудников бара. Сотрудник умеет выполнять все базовые функции бармена, при этом, есть возможность повысить его квалификацию, что в конечном счете сможет привести к повышению и дальнейшему карьерному росту.

С выведением такого сотрудника в график, бар будет отдавать заказы вовремя, при этом не выводя на смену сотрудника, добавляя к его двенадцатичасовой смене еще два оплачиваемых часа. На смене будет находиться помощник бармена, чья ставка меньше, соответственно и нагрузка на сотрудника распределена правильно, так как его рабочий день равен восьми часам.

Проанализировав процесс управления качеством на предприятии ресторана Марчеллис и применив диаграмму Исикавы для нахождения проблем качества, были выявлены недостатки, связанные со скоростью отдачи заказа. Предложенный выход из ситуации, гарантирует предприятию повышение качества сервиса данного подразделения, при этом не потребует экономических затрат.

Список литературы:

1. Лощилина И.В. Современные технологии управления. - Журнал "Методы менеджмента качества" №10, $2008 . \quad$ http://www.businessstudio.ru/procedures/iso/ishikava/

2. Анализ причинно-следственных связей. Перевод научного доклада [Электронный ресурс]. - http://analyst.com URL: http://analyst.by/articles/analiz-prichinnosledstvennyih-svyazey-perevod

3. Печерица Е.В., Шевченко М.И. Инновационные технологии в гостиничном бизнесе. Монография / Санкт-Петербургский государственный университет сервиса и экономики. Санкт-Петербург, 2013. 135 с.

4. Печерица Е.В. Позиционирование предприятий индустрии гостеприимства в условиях конкуренции. Монография / Е. В. Печерица; М-во образования и науки Российской Федерации, Федеральное агентство по образованию, Санкт-Петербургский гос. ун-т сервиса и экономики. Санкт-Петербург, 2010. 163 с.

5. Печерица Е.В. Категоризация и оценка качества гостиничных услуг. Монография / Санкт-Петербургский государственный университет сервиса и экономки. Санкт-Петербург, 2010. 239 с.

6. Рубан Д.А. Инновационный менеджмент в туризме: направления и управленческие действия. Вестник УрФУ. Серия: Экономика и управление. 2015. Т. 14. № 1. С. 114-126. 